\title{
The Aging Degree Analysis of EPR Cable Insulation Based on Hardness Retention Rate Measurement
}

\author{
Meng Xiao-Kai ${ }^{1 *}$, Han Pei-Jie ${ }^{2}$, Liu Xinyuan ${ }^{1}$ and Jin Tao ${ }^{1}$ \\ ${ }^{1}$ State Grid Shanxi Electric Power Research Institute, Shanxi, China \\ ${ }^{2}$ State Grid Shanxi Electric Power Corporation, Shanxi, China
}

\begin{abstract}
Based on the accelerated thermal aging analysis of Ethylene-Propylene Rubber (EPR) cables, the theoretical relationship between elongation at break retention rate $(E A B \%)$ and hardness retention rate was deduced from the mathematical principles of hardness test. The relation curve was compared with the measurement values, and the result shows that there is high coincidence degree between theoretical curve and measurement values. After researching on the experimental data of EAB\% and hardness retention rate, combining the "time-temperature shift factors" with Arrhenius equation, the lifetime termination index on account of hardness retention rate is analyzed when the EAB\% reduced to $30 \%-50 \%$. According to comparing theoretical values with the experimental results, hardness retention rate decreased to $10 \%$ was proposed as the lifetime termination index of EPR cable.
\end{abstract}

Keywords: Ethylene-propylene rubber cable; Elongation at break retention rate; Hardness retention rate; Time-temperature shift factor

\section{Introduction}

As the core of energy transfer in the process of power transmission and distribution, power cables are the key equipments to ensure the normal operation of power facilities [1-3]. Under the normal operation condition, cables may be exposed to high heat, humidity, thermal and mechanical shock, which will lead to lose their characteristics earlier than expected and accelerate their aging [4-6]. Because of the restriction of installation condition, most cables are laid in bundle and on suspension, which also will lead heat hard to disperse and cause temperature rising [7]. How to accurately assess the aging and insulation state of power cables is important practically so as to ensure the safe reliable operation of the ships.

Domestic and international research results show, it is remarkable that the surface hardness measurement of insulating material is used to reflect the aging rule. The work by Giannakopoulos and Suresh [8] has clearly shown that the hardness is proportional to the aging time. The authors $[9,10]$ have demonstrated that there is correlativity between the elongation at break and hardness. Wang Hx [7] has presented the cable life could be tested by the remaining hardness retention rate, but the computational process needs to know the initial hardness. The initial hardness of products from different companies in different years may be different, which will cause errors in the calculation results.

In the paper, $0.6 / 1 \mathrm{kV}$ EPR cables were studied and the ageing process was simulated vastly. Then the $\mathrm{EAB} \%$ and Hardness Retention Rate of the specimens after aging were measured. Combining with theoretical calculations and experimentation, the correlation between $\mathrm{EAB} \%$ and hardness retention rate was derived. The life prediction in view of hardness retention rate was analyzed by judgments standard of $\mathrm{EAB} \%$. Experimental life index was basically consistent with the value by $\mathrm{EAB} \%$, which proves the feasibility of the method and provides theoretical basis for non-destructive and online monitoring of the cables.

\section{Experimental Methods}

\section{Accelerated thermal aging}

According to the IEC 60811-1-1:2001, IDT, the shape and dimension of dumb-bell specimens were shown in Figure 1. According to American power station specifications and IEC 60216, the accelerated thermal aging temperatures were selected for $120^{\circ} \mathrm{C}, 135^{\circ} \mathrm{C}, 150^{\circ} \mathrm{C}$ and $165^{\circ} \mathrm{C}$. Electric ovens with air circulating fans were used to accelerate specimens aging. Five cable samples were located at every temperature for different periods of time, which were shown in Table 1.

\section{Tensile testing}

According to IEC60216-6: 2004, the sample should be exposed to the lowest temperature for $48 \pm 6$ hours before measuring the initial performance. In this paper, 10 dumb-bell specimens were exposed to minimum temperature of $120^{\circ} \mathrm{C}$ for 48 hours before aging and cooled in vacuum bags for 16 hours. The JDL-1000 micro-electronic tensile testing machine (tensile speeds of $50 \mathrm{~mm} / \mathrm{min}$ ) was used to measure the initial elongation at break. Eight specimens of each sampling period at every temperature were taken as a group and data in line was considered qualified after stretching, and the average value of the group was the actual measurement. As shown in Figure 2, sample 1-3 were qualified and sample 4 is invalid.

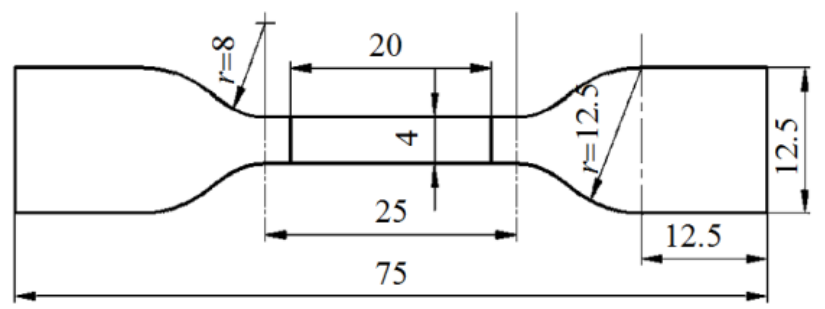

Figure 1: Dimension of a dumb-bell specimen $(\mathrm{mm})$

*Corresponding author: Meng Xiao-Kai, State Grid Shanxi Electric Power Research Institute, Shanxi, China, Tel: 86258309; E-mail: mengxiaokai870618@163.com

Received April 01, 2017; Accepted April 27, 2018; Published May 02, 2018

Citation: Xiao-Kai M, Pei-Jie H, Xinyuan L, Tao J (2018) The Aging Degree Analysis of EPR Cable Insulation Based on Hardness Retention Rate Measurement. J Electr Electron Syst 7: 260. doi: 10.4172/2332-0796.1000260

Copyright: ( 2018 Xiao-Kai M, et al. This is an open-access article distributed under the terms of the Creative Commons Attribution License, which permits unrestricted use, distribution, and reproduction in any medium, provided the original author and source are credited. 
Citation: Xiao-Kai M, Pei-Jie H, Xinyuan L, Tao J (2018) The Aging Degree Analysis of EPR Cable Insulation Based on Hardness Retention Rate Measurement. J Electr Electron Syst 7: 260. doi: 10.4172/2332-0796.1000260

Page 2 of 6

\begin{tabular}{|c|c|c|c|c|c|c|c|c|}
\hline Temperature & & & & & & & & \\
\hline $120^{\circ} \mathrm{C}$ & 120 & 192 & 264 & 456 & 648 & 1108 & 1440 & 2088 \\
\hline $135^{\circ} \mathrm{C}$ & 96 & 192 & 240 & 360 & 456 & 648 & 1108 & 1272 \\
\hline $150^{\circ} \mathrm{C}$ & 48 & 96 & 144 & 192 & 240 & 288 & 312 & 324 \\
\hline $165^{\circ} \mathrm{C}$ & 24 & 36 & 48 & 60 & 72 & 84 & 96 & 108 \\
\hline
\end{tabular}

Table 1: Experimental temperatures and sampling periods.

\begin{tabular}{|c|c|c|c|c|c|c|c|c|c|}
\hline Number & 1 & 2 & 3 & 4 & 5 & 6 & 7 & 8 & Average \\
\hline Hardness (HA) & 61 & 63 & 64 & 61 & 61 & 61 & 62 & 63 & 62 \\
\hline P (\%) & 39 & 37 & 36 & 39 & 39 & 39 & 38 & 37 & 38 \\
\hline EAB (\%) & 698.73 & 703.21 & 710.38 & 696.23 & 698.71 & 691.98 & 699.14 & 703.22 & 700.2 \\
\hline
\end{tabular}

Table 2: The initial data of the aging experiment.

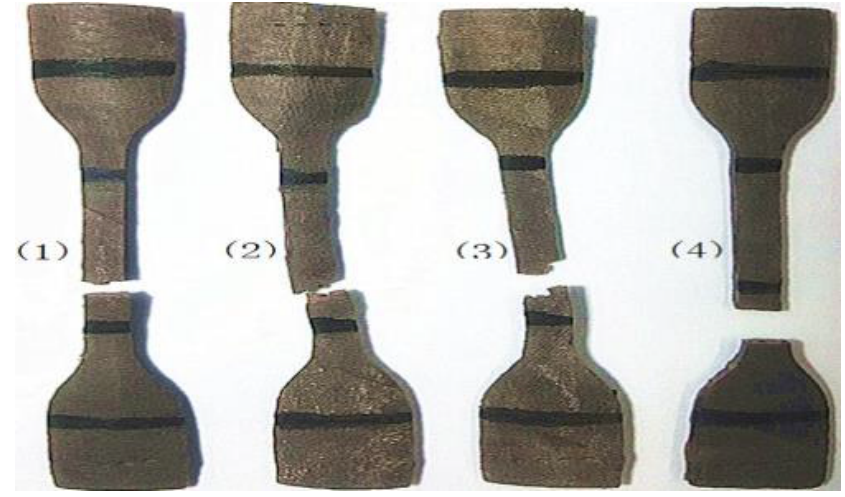

Figure 2: Judgment standard of data.

\section{Hardness retention rate}

When the surface of the cables was pressed vertically with steel probe, the hardness retention of the cables was measured and the method of aging evaluation is nondestructive.

According to Chinese national standard of GB/T531.1-2008, ISO 7619-1:2004 Shore AM durometer was used to test the hardness. The hardness values of eight samples were measured at each temperature and time, and five different measurement points were selected for each sample as shown in Figure 3. The average value was taken as the actual measurement value.

On basis of property variation rate during aging in the regulation of GB/T 3512-2014, the hardness retention was proposed in this paper and the equation was described as:

$$
\mathrm{P}=\frac{100-X}{100} \times 100 \%
$$

Where: $\mathrm{P}=$ hardness retention rate, $X=$ the hardness value after aging.

The initial average values of $\mathrm{EAB}(\%)$, hardness and $\mathrm{P}$ are shown in Table 2.

\section{The Relationship between EAB\% and P}

The hardness value is determined by the degree of compression deformation, and the $\mathrm{EAB} \%$ is determined by the tensile stress. The relationship between $\mathrm{EAB} \%$ and $\mathrm{P}$ was analyzed from the aspect of mechanics and molecular conformation theory in this paper.

\section{Mechanics theory}

In terms of measurement principle of Shore AM durometer, the

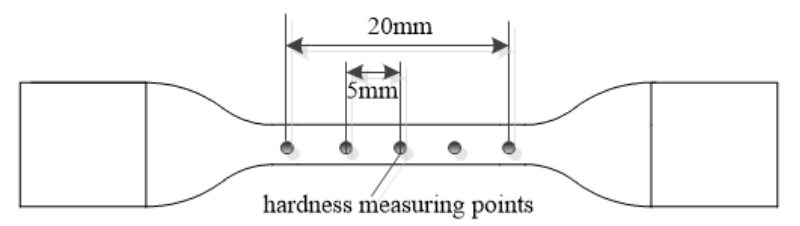

Figure 3: Schematic diagram of hardness measuring points.

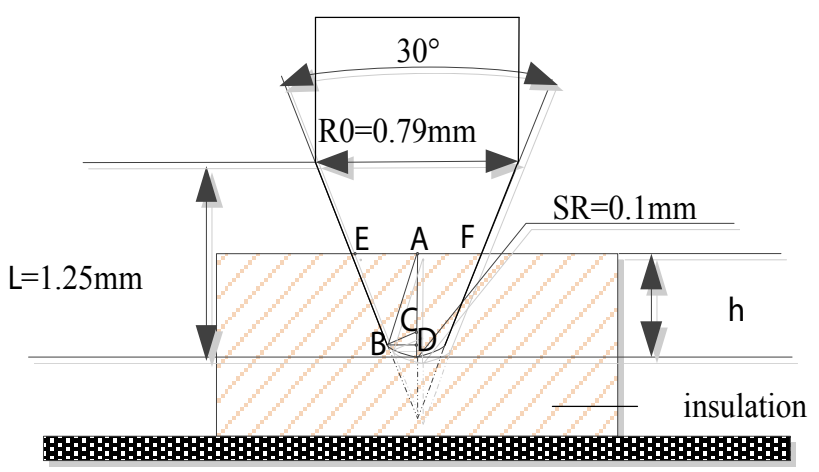

The base of hardness tester

Figure 4: Working principle of hardness tester.

pressure head of which is shown in Figure 4, the hardness value is determined by the depth pressed into the sample.

$$
H=100-h / 0.0125
$$

Where: $H=$ hardness, HA. $h=$ depth, mm.

In Figure 4, point $\mathrm{E}, \mathrm{F}$ and $\mathrm{B}$ are the cross point of pressure head and the sample, point $A$ is the center of section $S_{A E F}$, point $C$ is the center of pressure head arc, D is the center of projection plane, and the depth pressed into the sample is $h$.

$S_{A E F}=2 \pi R_{E A} t$

Where: $t$ is the thickness of unit area in the direction of tensile test.

It is assumed that the volume of the sample remains constant during the compression process, and the sphere at the top of the head is approximated to a plane.

So,

$\pi\left(R_{E A}+r\right) t \sqrt{\left(R_{E A}-r\right)^{2}+h^{2}}=\pi R_{E A}^{2} t_{0}$

Where, $t_{0}$ is the initial thickness, $r=\mathrm{SR} / 2 \cdot \cos 15^{\circ}$.

Simultaneous eqns. (3) and (4), 


$$
S_{A E F}=\frac{2 \pi R_{E A}^{3} t_{0}}{\left(R_{E A}+r\right) \sqrt{\left(R_{E A}-r\right)^{2}+h^{2}}}
$$

The authors [11] have shown that the surface pressure of the sample is equal and perpendicular to the surface. The decomposition diagram of the pressure is shown as Figure 5.

The constant force $\mathrm{F}(5 \mathrm{~N})$ can be decomposed into $\mathrm{F}_{1}$ and $\mathrm{F}_{2}$, which is respectively perpendicular and parallel to the lateral surface. The force which works on the surface is $\mathrm{F}_{1}$, and $\mathrm{F}_{2}$ overcomes the friction in the extrusion process.

$$
F_{1}=F \cos \delta
$$

Where: $\delta$ is the included angle between $F$ and $F_{1}$.

Therefore, the stress $\sigma$ produced by $F_{1}$ is:

$$
\sigma=\frac{F \cos \delta}{S_{A E F}}=\frac{F \cos \delta\left(R_{E A}+r\right) \sqrt{\left(R_{E A}-r\right)^{2}+h^{2}}}{2 \pi R_{E A}^{3} t_{0}}
$$

When the test force $\mathrm{F}$ is constant, the stress $\sigma$ decreases as the cross section area of the head pressed into the sample increases gradually with the increase of the depth. The average value of stress is analyzed so as to reduce the error in this paper. The radius of cross section $S_{A E F}$ can be determined as $R_{E A}=R_{0} / 4$.

$$
\sigma=\frac{F \cos \delta\left(\frac{R_{0}}{4}+r\right) \sqrt{\left(\frac{R_{0}}{4}-r\right)^{2}+h^{2}}}{2 \pi\left(\frac{R_{0}}{4}\right)^{3} t_{0}}
$$

\section{Molecular conformation theory}

Jin [12] has reported that for the isotropic rubber samples, conformation entropy of chain is shown as Figure 6.

$$
\Delta S=-\frac{1}{2} N k\left(\lambda_{1}^{2}+\lambda_{2}^{2}+\lambda_{3}^{2}-3\right)
$$

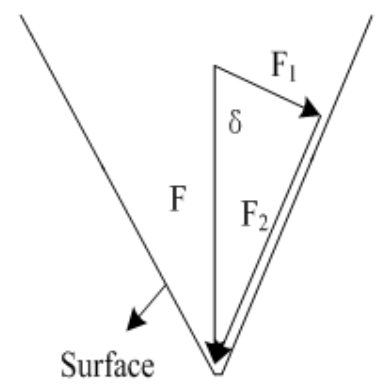

Figure 5: The pressure decomposed of indenter.

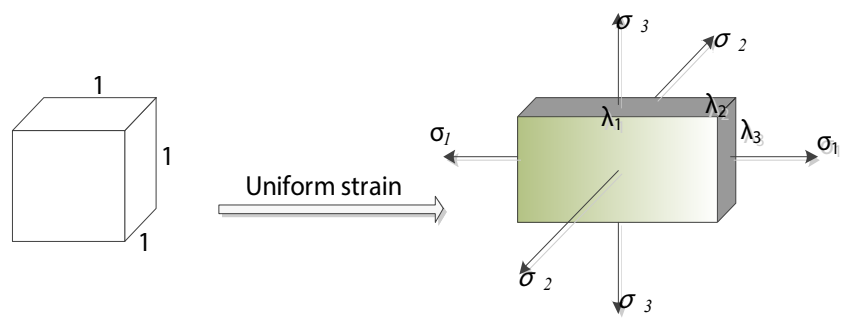

Figure 6: Uniform strain state of isotropic rubber samples.
Where, $\lambda_{1}, \lambda_{2}, \lambda_{3}$ is draw ratio in three directions, $\lambda_{1} \lambda_{2} \lambda_{3}=1, \Delta S$ is total entropy, $N$ is total number of chain, $k$ is gas constant.

Because the length and width of the samples remain constant during the compression process, it is considered that there is only uniaxial deformation in the direction of thickness. Therefore, $\lambda_{1}=\lambda, \lambda_{2}=\lambda_{3}$, where $\lambda$ is uniaxial tension ratio.

$$
\Delta S=-\frac{1}{2} N k\left(\frac{2}{\lambda}+\lambda^{2}-3\right)
$$

As the internal energy of the cross-linked network keeps constant during deformation, work done by external forces is equal to the increment of free energy $\Delta F$.

$$
\begin{aligned}
& W=\Delta F=-T \Delta S \\
& d W=f d t \\
& f=\frac{d W}{d t}=\frac{d W}{d \lambda} \cdot \frac{d \lambda}{d t}=\frac{1}{t_{0} / \lambda} N k T\left(\lambda-\frac{1}{\lambda^{2}}\right) \\
& \sigma=\frac{f}{A}=\frac{1}{A t_{0}} N k T\left(\lambda^{2}-\frac{1}{\lambda}\right)=N_{1} k T\left(\lambda^{2}-\frac{1}{\lambda}\right)
\end{aligned}
$$

Where, $f$ is tensile force along the thickness, $T$ is the absolute temperature, $t$ is thickness after stretching, $A$ is pressure area, $N_{1}$ is chain number per unit volume.

Because the tensile stress and compressive stress of rubber material are equal in a certain range, the relationship between tensile ratio and pressed depth can be calculated according to eqns. (8) and (14).

$$
\left.h=\left[\frac{2 \pi(-)^{3} t_{0} N_{1} k T\left[\lambda^{2}-\right]}{F \cos (-r)}\right)^{2}-(--r)^{2}\right]^{-}
$$

The relationship between tensile ratio and $\mathrm{EAB} \%$ is

$\lambda=\frac{l_{0}+\Delta l^{\prime}}{l_{0}}=1+E^{\prime}$

The formulas of the $\mathrm{EAB} \%$ are

$$
\begin{aligned}
& \mathrm{EAB} \%=\frac{E^{\prime}}{E} \\
& E=\frac{\Delta l}{l_{0}} \times 100 \% \\
& E^{\prime}=\frac{\Delta l^{\prime}}{l_{9}}
\end{aligned}
$$

Therefore,

$$
\lambda=1+\mathrm{EAB} \% \times E
$$

Where, $l_{0}=20 \mathrm{~mm}, \Delta l$ is the marking spacing variation before breaking, $E$ is the initial value of $\mathrm{EAB} \%, E^{\prime}$ is $\mathrm{EAB} \%$ after aging, $\Delta l^{\prime}$ is the marking spacing variation before breaking after aging.

There are elastic and plastic deformation in sequence during tensile process, but tensile ratio only includes elastic deformation, so that the actual value of $E^{\prime}$ is greater than $\lambda-1$. The eqn. (15) can be expressed as,

$$
\left.h=C\left[\frac{2 \pi\left(\frac{R_{0}}{4}\right)^{3} t_{0} N_{1} k T\left[(1+E A B \% \times E)^{2}-\frac{1}{(1+E A B \% \times E)}\right.}{F \cos \delta\left(\frac{R_{0}}{4}+r\right)}\right)^{2}-\left(\frac{R_{0}}{4}-r\right)^{2}\right]^{\frac{1}{2}}
$$

Then taking the initial value of Table 2 into eqn. (21), it could be known that $C=0.02954$. And the relationship between $\mathrm{EAB} \%$ and $\mathrm{P}$ can 
be deduced on the basis of the relationship between indentation depth and $\mathrm{EAB} \%$.

$$
\begin{gathered}
P=2.3632 \times\left\{0.3021 \times N_{1} k T\left[(1+7.002 E A B \%)^{2}\right.\right. \\
\left.\left.-\frac{1}{1+7.002 E A B \%}\right]^{2}-0.02176\right\}^{\frac{1}{2}}
\end{gathered}
$$

In order to verify the correctness of the theoretical equations, the fitting curve is established as shown in Figure 7. When EAB\% is $100 \%$ and $50 \%, \mathrm{P}$ is $38.8 \%$ and $9.75 \%$, respectively as seen here. The result is close to the initial value of the experiment, which proves the feasibility that hardness retention rate is used for life prediction.

\section{Experimental Data Analysis and Life Prediction}

Above all, $\mathrm{EAB} \%$ and $\mathrm{P}$ have high similarity in life prediction of cables. Since there are not national standards of the lifetime termination in view of hardness retention rate, this paper aimed to propose the lifetime termination index of hardness retention rate according to the experimental data after aging.

\section{Time-temperature superposition method}

Correspondence between the time and the temperature can be achieved by time-temperature shift [13-15] with suitable shift factors $\alpha_{T i}$ it could be described as eqn. (23):

$$
\alpha_{T i}=\frac{t_{r e f i}}{t_{i}}
$$

The shift factors are correlated with the temperature by Arrhenius equation as eqn. (24):

$$
\lg \alpha_{T i}=\frac{E_{a}}{R}\left(\frac{1}{T_{r e f}}-\frac{1}{T}\right)
$$

In order to calculate the reliability of the time-temperature shift factors at each temperature, an optimal calculation method was proposed as:

$$
L^{2}=\frac{S_{x y}^{2}}{S_{x x} \cdot S_{y y}}
$$

Where:

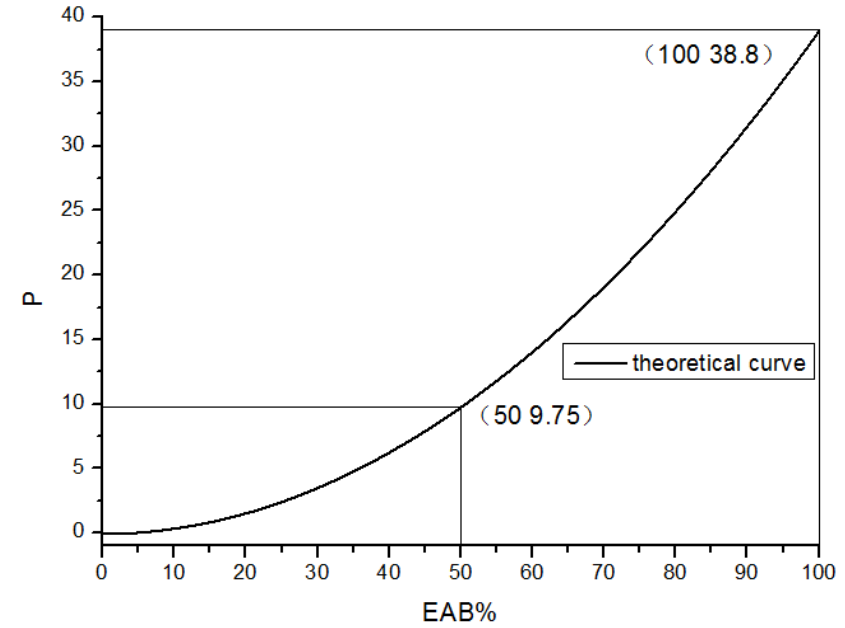

Figure 7: The theoretical relation between $\mathrm{EAB} \%$ and $\mathrm{P}$.

$$
\begin{aligned}
& S_{x x}=\sum_{i=1}^{m} \sum_{j=1}^{n_{i}}\left(\alpha_{T_{i}} \cdot t_{i j}\right)^{2}-\frac{1}{\sum_{i=1}^{m} n_{i}}\left(\sum_{i=1}^{m} \sum_{j=1}^{n_{i}} \alpha_{T_{i}} \cdot t_{i j}\right)^{2} \\
& S_{y y}=\sum_{i=1}^{m} \sum_{j=1}^{n_{i}}\left(w_{i j}\right)^{2}-\frac{1}{\sum_{i=1}^{m} n_{i}}\left(\sum_{i=1}^{m} \sum_{j=1}^{n_{i}} w_{i j}\right)^{2} \\
& S_{x y}=\sum_{i=1}^{m} \sum_{j=1}^{n_{i}} \alpha_{T_{i}} \cdot t_{i j} \cdot w_{i j}-\frac{1}{\sum_{i=1}^{m} n_{i}}\left(\sum_{i=1}^{m} \sum_{j=1}^{n_{i}} \alpha_{T_{i}} \cdot t_{i j}\right) \cdot\left(\sum_{i=1}^{m} \sum_{j=1}^{n_{i}} w_{i j}\right)
\end{aligned}
$$

Where: $\alpha_{T 1}=1, \alpha_{T i}>1(i=2, \ldots, \mathrm{m}=4), i=$ sequence number of each temperature, $j=1, \ldots . \mathrm{n}_{i}=8$ sequence number of $i, w_{\mathrm{ij}}=$ the insulation property variation rate, $t_{\mathrm{ij}}=$ aging time, $L=$ the correlation coefficient of fitting.

The experimental data of $\mathrm{EAB} \%$ and hardness retention rate is shown as Table 3.

According to time-temperature superposition theory, thermal aging temperature of $120^{\circ} \mathrm{C}$ was selected as the reference temperature, the values of $\mathrm{EAB} \%$ and hardness retention rate at each higher temperature of $135^{\circ} \mathrm{C}, 150^{\circ} \mathrm{C}$ and $165^{\circ} \mathrm{C}$ shifted horizontally, so as to create master curves of measurements at different temperatures.

As shown in Figures 8 and 9, the shift factors of $\mathrm{EAB} \%$ and $\mathrm{P}$ were (18 6.41 .61 ) and (17 5.8 1.6 1), respectively. It is clear that the change curves of $\mathrm{EAB} \%$ and $\mathrm{P}$ at different temperatures have the same shape and show excellent superposition. The fitting curve equations were described as eqn. (29):

$$
\left\{\begin{array}{l}
E A B \%=-16.24 \times e^{(\mathrm{x} / 1202.77)}+111.54 \\
P \%=-50.963 \times e^{(x / 4884.06)}+81.9629
\end{array}\right.
$$

\begin{tabular}{|c|c|c|c|c|c|c|c|}
\hline $\mathrm{T} /{ }^{\circ} \mathrm{C}$ & Time/h & EAB $\%$ & $\mathbf{P}(\%)$ & $\mathrm{T} /{ }^{\circ} \mathrm{C}$ & Time/h & EAB \% & $\mathbf{P}(\%)$ \\
\hline \multirow[t]{8}{*}{$120^{\circ} \mathrm{C}$} & 120 & 97.7 & 31.4 & \multirow[t]{8}{*}{$135^{\circ} \mathrm{C}$} & 96 & 94.8 & 30 \\
\hline & 192 & 94.3 & 30.8 & & 192 & 90 & 28.8 \\
\hline & 264 & 92.5 & 30.2 & & 240 & 88.1 & 27.7 \\
\hline & 456 & 85.8 & 27.4 & & 360 & 84.4 & 26.5 \\
\hline & 648 & 78.8 & 25 & & 456 & 78.8 & 25.8 \\
\hline & 1108 & 67.1 & 19 & & 648 & 70 & 23 \\
\hline & 1440 & 56.1 & 16 & & 1108 & 48 & 14 \\
\hline & 2088 & 15.2 & 7 & & 1272 & 22.2 & 9 \\
\hline \multirow[t]{8}{*}{$150^{\circ} \mathrm{C}$} & 48 & 90.1 & 29 & \multirow[t]{8}{*}{$165^{\circ} \mathrm{C}$} & 24 & 88.3 & 28.6 \\
\hline & 96 & 83.4 & 28.2 & & 36 & 82.6 & 27.8 \\
\hline & 144 & 79.6 & 26.4 & & 48 & 76.8 & 27 \\
\hline & 192 & 70.6 & 24 & & 60 & 70.3 & 25 \\
\hline & 240 & 60.3 & 20 & & 72 & 64.8 & 21 \\
\hline & 288 & 45 & 14 & & 84 & 60.8 & 17 \\
\hline & 312 & 22.9 & 11 & & 96 & 54 & 14 \\
\hline & 324 & 18.7 & 8 & & 108 & 27.3 & 10 \\
\hline
\end{tabular}

Where: $\mathrm{x}$ is the aging time at $120^{\circ} \mathrm{C}$.

The corresponding relation curve is shown as Figure 10 on basis of eliminating time variable and the result is consistent with the theoretical curve.

\section{Calculation of activation energy}

According to Arrhenius equation, the reaction rate $k$ is proportional to $\exp \left(-E_{\mathrm{a}} / \mathrm{R} T\right)$,

Table 3: The experimental data of $E A B \%$ and hardness retention. 


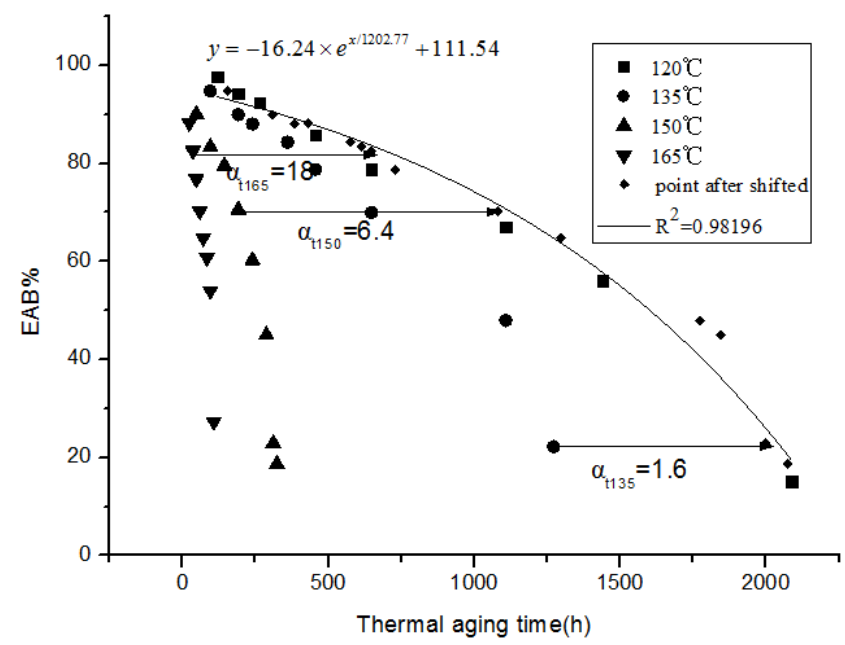

Figure 8: The fitting curve of EAB\%.

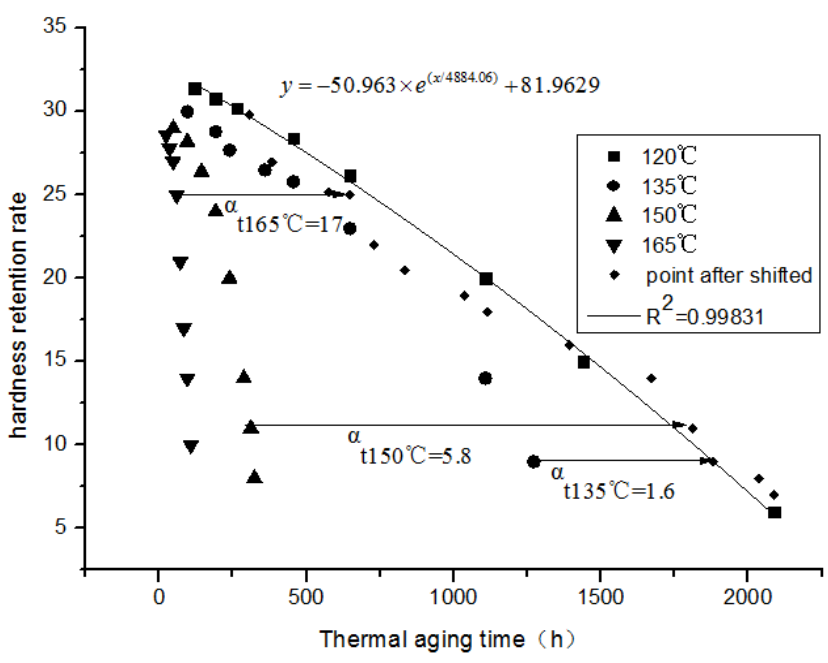

Figure 9: The fitting curve of hardness retention rate.

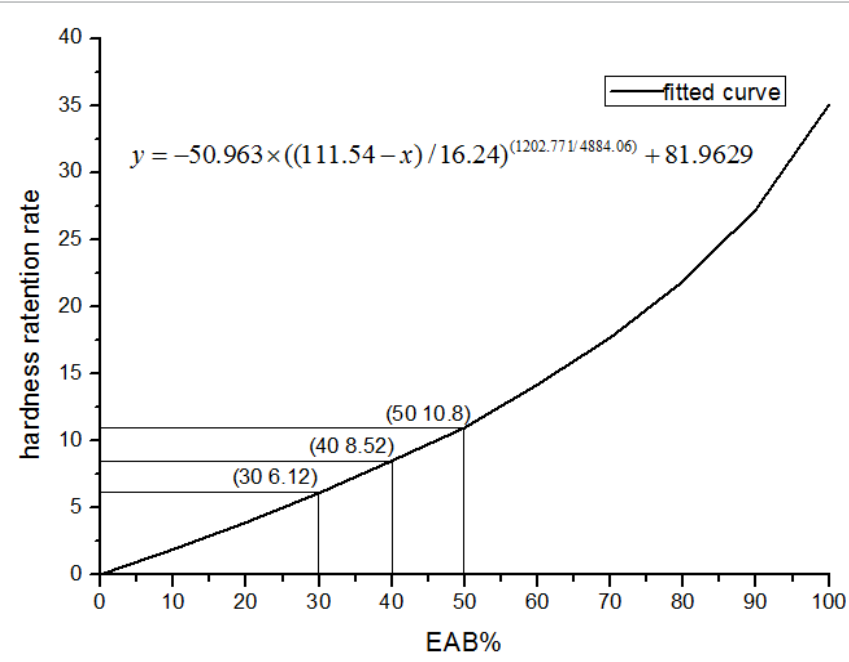

Figure 10: The relationship between $E A B \%$ and $P$.

$$
k=A \cdot \exp \left(\frac{-E_{a}}{R T}\right)
$$

Where $E_{\mathrm{a}}$ is the Arrhenius activation energy, $\mathrm{R}$ is the gas Moore constant $(8.314 \mathrm{~J} / \mathrm{mol}-\mathrm{K}), T$ is the absolute temperature and $\mathrm{A}$ is the pre-exponential factor (eqn. 30 )

As the reaction time $t$ is inversely proportional to $\mathrm{k}$ and $\alpha_{\mathrm{T}}$ is inversely proportional to $t$, any activation energy in temperature range $\left(T_{1}-T_{2}\right)$ can be determined via eqn. (32).

$$
\begin{aligned}
& k_{i}=\frac{1}{t_{i}} \propto \alpha_{T i} \\
& \frac{a_{T 1}}{a_{T 2}}=\frac{A^{\prime} \cdot \exp \left(\frac{-E_{a}}{R T_{1}}\right)}{A^{\prime} \cdot \exp \left(\frac{-E_{a}}{R T_{2}}\right)}=\exp \left(\frac{E_{a}}{R}\left(\frac{1}{T_{2}}-\frac{1}{T_{1}}\right)\right)
\end{aligned}
$$

When $\alpha_{T 2}=1, \mathrm{~T}_{2}=120^{\circ} \mathrm{C}=393 \mathrm{~K}$,

$$
\text { In } a_{T}=\frac{E_{a}}{R}\left(\frac{1}{393}-\frac{1}{T}\right)
$$

To demonstrate the suitability of fitting curve in view of eqn. (33) the accelerative shift factors were re-examined. The data can be fitted as shown in Figure 11 and activation energy of EAB\% and P are 120.024 $\mathrm{kJ} / \mathrm{mol}$ and $118.890 \mathrm{~kJ} / \mathrm{mol}$ respectively.

\section{Life prediction}

Traditional Arrhenius analysis of EAB\% usually picks out the time corresponding to a certain amount of 30\%-50\% degradation, but hardness test has no approved standard. In order to provide standard to determine the life through the hardness test, this paper correlates hardness retention rate with $\mathrm{EAB} \%$ data to assess current condition and useful life of cables.

According to eqn. (29) and activation energy, the lifetime of cables under different temperatures as shown in Table 4. It can be seen that the errors between $\mathrm{EAB} \%$ and $\mathrm{P}$ at different temperatures were very small. When $\mathrm{EAB} \%$ were selected for $50 \%, 40 \%$ and $30 \%$ degradation, the termination index of $\mathrm{P}$ were $10.8 \%, 8.52 \%$ and $6.12 \%$. And it shown that when the working temperatures were $70^{\circ} \mathrm{C}, 75^{\circ} \mathrm{C}, 80^{\circ} \mathrm{C}$ and $85^{\circ} \mathrm{C}$, the maximum difference were $2.3 \mathrm{a}, 1.1 \mathrm{a}, 0.5 \mathrm{a}$ and $0.2 \mathrm{a}$. It was proved

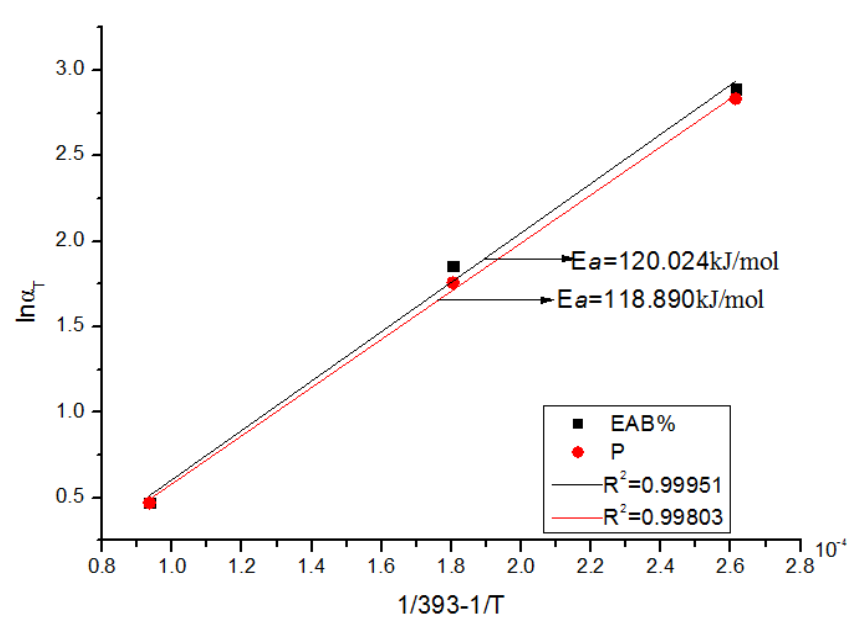

Figure 11: The Arrhenius plot of the shifting factors at a reference temperature of $120^{\circ} \mathrm{C}$. 
Citation: Xiao-Kai M, Pei-Jie H, Xinyuan L, Tao J (2018) The Aging Degree Analysis of EPR Cable Insulation Based on Hardness Retention Rate Measurement. J Electr Electron Syst 7: 260. doi: 10.4172/2332-0796.1000260

\begin{tabular}{|l|l|l|l|l|}
\hline \multicolumn{1}{|c|}{$\mathbf{T}$} & $\mathbf{7 0}^{\circ} \mathbf{C}$ & $\mathbf{7 5}^{\circ} \mathbf{C}$ & $\mathbf{8 0}^{\circ} \mathbf{C}$ & $\mathbf{8 5}^{\circ} \mathbf{C}$ \\
\hline EAB\%=50\% & 38.7 & 21.1 & 11.7 & 6.6 \\
\hline $\mathbf{P \% = 1 0 . 8 \%}$ & 37.1 & 20.4 & 11.4 & 6.5 \\
\hline EAB\%=40\% & 43.1 & 23.5 & 13.1 & 7.4 \\
\hline $\mathbf{P \% = 8 . 5 2 \%}$ & 41.0 & 22.5 & 12.6 & 7.2 \\
\hline EAB\%=30\% & 46.9 & 25.6 & 14.2 & 8.0 \\
\hline $\mathbf{P \% = 6 . 1 2 \%}$ & 44.6 & 24.5 & 13.7 & 7.8 \\
\hline
\end{tabular}

Table 4: The aging lifetime of cable under different temperatures and end levels.

that the nondestructive evaluation method based on hardness retention rate can predict the lifetime well.

Due to non-destructive testing, combining comprehensive theoretical curve and actual measurement results, taking account of safety margin, the hardness retention rate reduced to $10 \%$ is used as lifetime termination index. As long as the hardness retention and operating temperature of the same type of cables are provided under current condition for on-site test, the life of the cables can be quickly deduced from the formulas, which provides new ideas for life assessment of cables.

\section{Conclusions}

In this paper, marine ethylene-propylene rubber cables were studied and hardness retention rate was used for thermal aging assessment. The following conclusions can be drawn:

- The relationship between $\mathrm{EAB} \%$ and $\mathrm{P}$ is deduced by combining the theories and experiments. Meanwhile, it demonstrates that hardness retention rate can be used to predict the lifetime well.

- As the termination index that $\mathrm{EAB} \%$ was reduced to $50 \%$, hardness retention rate was $10.8 \%$.Taking the other factors into consideration, $10 \%$ of hardness retention rate was chosen as the termination index.

- In this paper, the detection method of hardness retention rate is nondestructive for cables. It only needs to know the hardness retention rate in the process of test, so that the remaining life of the cables could be calculated.

\section{Acknowledgements}

The authors would like to appreciate support from the international science and technology cooperation program of china, the doctoral start fund of Liaoning province, and the fundamental research funds for the central universities.

\section{References}

1. Lei Z, Song J, Tian M, Geng P, Chuanyang L, et al. (2014) Influence of cavities on the dielectric properties of Ethylene Propylene Rubber insulation. Proceedings of 2014 International Symposium on Electrical Insulating Materials; pp: $437-440$

2. Grzybowski S, Cao L, Pushpanathan B (2009) Accelerated electrica degradation of $15 \mathrm{kV}$ EPR cable under dry and wet condition energized by switching impulses. North American Power Symposium; pp: 1-5.

3. Kang WB (2002) The effect of insulating property of ship power grid on the safety of ship navigation. Jiang Su Ship 19: 20-22.

4. Yi W (2012) Theoretical and experimental study on residual life prediction of shipboard low-voltage cable. Dalian: Dalian Maritime University.

5. Zhi-Qiang W, Chang-Liang Z, Wenwen L, Guofeng L (2012) Residual life assessment of Butyl Rubber insulation cables in ship-board. Proceedings of the China society of electrical engineering 34: 189-195.

6. Hsu YT, Chang-Liao KS, Wang TK (2007) Correlation between mechanica and electrical properties for assessing the degradation of ethylene propylene rubber cables used in nuclear power plants. Polymer degradation and stability 92: 1297-1303.

7. He-Xu W (2014) Study of the rule of ship cable insulation aging and rapid detection methods. Dalian: Dalian Maritime University.

8. Giannakopoulos AE, Suresh S (2000) Determination of elasto-plastic properties by instrumented sharp indentation: guidelines for property extraction. Script a Materialia 42: 1191-1198.

9. Kim JS (2007) Study of relational equation between indent for cable aging evaluation. Transactions of the Korean Nuclear Society Spring Meeting.

10. Arvia EM, Sheldon RT, Bowler N (2014) A capacitive test method for cable insulation degradation assessment. IEEE Conference on Electrical Insulation and Dielectric Phenomena (CEIDP); pp: 514-517.

11. Shijie $L$ (1984) The stress analysis of Rockwell and Vickers indenter and value transformation. Machine \& testing materials 4: 53-57.

12. Riguang J (2006) Polymer Physics. (3rd edn.), Beijing: Chemical Industry Press; pp: 160-217.

13. Lijun $Y$, Bangfei $D$, Ruijin $L$ (2011) Improvement of lifetime model on thermal aging of oil-paper insulation by time-temperature moisture superposition method. Proceedings of the China Society of Electrical Engineering 31: 196-203.

14. Umberger PD, Case SW, Cook FP (2011) Time-temperature superposition and high rate response of thermoplastic composites and constituents. Time Dependent Constitutive Behavior and Fracture/Failure Processes 3: 139-146.

15. Gillen KT, Celina M, Bernstein R (2003) Validation of improved methods fo predicting long-term elastomeric seal lifetimes from compression stressrelaxation and oxygen consumption techniques. Polymer degradation and Stability $82: 25-35$ 